view that any and all cooperation between industry and academics is inherently suspect has created a poisonous atmosphere that has driven some young investigators to take up other careers. So charged have things become that Robert Califf, vice-chancellor for clinical research at Duke University Medical Center in Durham, North Carolina, last week told a conference at NIH headquarters in Bethesda, Maryland, about a recent meeting where the leaders of major academic medical centres were afraid to sit in the same room with industry leaders - with the goal of enhancing understanding and cooperation - for fear of an outcry either in Congress or the media.

Yet such meetings, and appointments such as Chin's, are not only appropriate, but essential for strengthening university research and for bridging the gap between lab and clinic - a gap that has bred a justifiable public impatience for cures at the advent of the 'century of biology'.

Chin has both a physician's appreciation of illness and an enviable scientific pedigree; the chairs of the medical school's basic-science departments endorsed his hiring unanimously. He has always sought to connect laboratory discoveries to human disease. Just as importantly, he has run a huge drug-discovery enterprise, giving him the kind of management experience and insights into discovery and translation that can be got only in industry. This will particularly inform his efforts to guide the medical school's scientific interactions with industry, in the drive to meet critical medical needs.

Reject such people and the academy cuts off its nose to spite its face. Instead, it should take advantage of them, as the University of California, San Francisco (UCSF), did last year in naming Susan DesmondHellmann, previously president of product development at biotech company Genentech, as its chancellor. Last week, six months after she took the helm, UCSF announced a collaboration with Genentech aimed at generating small-molecule drug candidates, a step that has proven a major obstacle in drug discovery.

The notion, pushed implicitly by critics, that academia can and should remain a pristine bubble, untainted and uninformed by those with industry experience, reflects a failure to understand that industry-academia cooperation is essential if we are to speed the medical progress that everyone seeks.

\title{
An absurd law
}

\section{Turkey's government is about to pass legislation that could cripple the country's biological research.}

W hen politicians respond to popular distrust of genetically modified organisms (GMOs), they sometimes fail to grasp how intricately molecular technologies infiltrate different areas of science. A case in point is now playing out in Turkey, where an attempt to regulate GMOs in agriculture has morphed into a draft law that could wipe out the country's biomedical research.

Most of Turkey's scientists learnt about the situation only a few weeks ago. Some responded immediately, organizing meetings and petitions, and lobbying parliamentarians to try to stage a last-minute reprieve. But as Nature goes to press, it seems likely that the law will be voted in by parliament this week without change. Ironically, it will go through at a time when many universities in Turkey are expanding their activities in biomedical research.

The law was first drafted after Turkey signed up to the United Nations Environmental Programme's International Cartagena Protocol on Biosafety in 2000. This requires signatories to create legislation to regulate the international trade, handling and use of any GMO that might have adverse effects on biodiversity or human health.

Turkey was at the same time trying to align much of its legislation with that of the European Union, which it aspires to join. The first draft was prepared with input from Turkey's research council, TÜBİTAK, and followed European regulations that separate deliberate release of GMOs into the environment - cultivation of GM crops, for example - and the contained use of GMOs for research.

Before this draft could be made law, the government changed and the mildly Islamic AK Party took office in 2002. Responsibility for the law transferred from the environment ministry to the agriculture ministry, which did not consult with molecular biologists. Over the years, the draft law's form changed. At the same time, popular opposition to genetic engineering in general, and GM food in particular, increased.

The version now being voted on fails to distinguish between deliberate release and contained use. It includes an outright ban on the cultivation of all GM crops, even those whose safety has been assessed and approved by expert bodies. It also bans the generation of genetically manipulated animals and microorganisms.

The law does not forbid research using GMOs or products derived from genetic engineering, but it makes such research impracticable. Every individual procedure would have to be approved by an interministerial committee headed by the agriculture ministry, which is allowed 90 days to consider each application with the help of experts.

The committee would be responsible for approving applications to import tonnes of GM soya beans for food — but also for every experiment involving even the use of a standard plasmid to transfer genes into cells. Work with universally used model organisms, from mice and zebrafish to fruitflies and bacteria, would be rendered impossible. Even if scientists could afford to wait three months for approval of the simplest experiment, the committee would be overwhelmed by the number of applications. One Turkish scientist who has examined the law estimates that his lab alone would need to submit 50 or so separate applications in a year.

It is disappointing that so important a draft law should have got so far without full consultation with all the communities affected by it. It is also disappointing that TÜBİTAK, which is close to the government but should nevertheless defend scientific interests, has so far remained silent on the issue. The Turkish Academy of Sciences is planning to prepare a position paper, but it is moving too slowly.

Turkish scientists can only hope that their individual lobbying activities will influence the vote at the last minute. Officials insist that the law will not affect research but they misunderstand. The impact will be profound. The government, which almost certainly does not wish to harm its country's fragile research base, must open its eyes to the drastic consequences of this legislation. 